\title{
Pharmacologic reduction of sympathetic drive increases platelet alpha-2-receptor number
}

\begin{abstract}
Several lines of evidence implicate sympathetic nervous system involvement in the pathophysiology of essential hypertension in man. Extrapolations are frequently made from in vitro measurements of plasma catecholamine levels to the physiologic role of the sympathetic system in hypertension. We assessed the utility and validity of such extrapolation from in vitro to in vivo measures of adrenergic function. Addition of guanadrel to diuretic therapy in 11 patients with essential hypertension reduced supine intra-arterial blood pressure from $135 \pm 14 / 76 \pm 9$ to $127 \pm 13 / 67 \pm 5 \mathrm{~mm} \mathrm{Hg}(\mathrm{P}<0.02)$. Supine heart rate was also reduced, from $77 \pm 14$ to $63 \pm 13 \mathrm{bpm}(P<0.001)$. Plasma norepinephrine levels fell from $303 \pm 107$ to $170 \pm 46 \mathrm{pg} / \mathrm{ml}(\mathrm{P}<0.01)$. Platelet $\alpha_{2}$-receptor number $\left(\left[{ }^{3} \mathrm{H}\right]\right.$ yohimbine maximal binding $)$ increased from $204 \pm 77$ to $301 \pm 150 \mathrm{fmol} / \mathrm{mg}(\mathrm{P}<0.02)$. The pupillary mydriatic response to phenylephrine and the forearm arterial vasoconstrictor response to intra-arterial norepinephrine did not change. Thus guanadrel reduced blood pressure by decreasing sympathetic tonc. In this milieu of low sympathetic activity the platelet $\alpha_{2}$-receptor number increased, but physiologic responses to exogenous $\alpha$-agonists did not change. Caution is therefore advised when extrapolating from in vitro measurement of plasma catecholamine levels and platelet $\alpha_{2}$-receptor number to the in vivo physiologic significance.
\end{abstract} (Clin Pharmacol Ther 1985;38:519-24.)

\section{Brent Egan, M.D., Richard Neubig, M.D., Ph.D.* and Stevo Julius, M.D., Sc.D. Ann Arbor, Mich.}

A number of investigators have identified an important pathophysiologic role for the sympathetic nervous system in essential hypertension in man. Studies in our laboratory showed a crucial role for the adrenergic system in maintaining the elevated cardiac output and heart rate in borderline hypertension. ' Despite normal cardiac output, patients with elevated plasma renin activity and either borderline or mild hypertension maintained a higher blood pressure through increased neurogenic vasoconstriction. ${ }^{2.3}$ Other investigators reported increased pressor responsiveness to exogenous norepinephrine, but normal responses to angiotensin, in both borderline and established essential hypertension. ${ }^{4,5}$ Studies evaluating local vascular responses also showed a similar

From the Division of Hypertension, Department of Internal Medicine, University of Michigan Medical Center.

Supported by Grant No. 1K08 HLO 1353 from the National Institutes of Health, by Grant No. 84-522-J1 from the American Heart Association (Michigan affiliate), and by Pennwalt Pharmaceuticals.

Received for publication March 25, 1985; accepted June 18, 1985.

Reprint requests to: Brent Egan, M.D., Division of Hypertension, R6669 Kresge Medical Research Bldg. \#1, University of Michigan Medical Center, Ann Arbor, MI 48109-0010.

*Recipient of a Hartford Foundation Fellowship. heightened sensitivity to both exogenous and endogenous norepinephrine..$^{6,7}$

Because of the potential importance of the adrenergic system in essential hypertension, methods for precise evaluation of sympathetic function would be useful. Plasma catecholamine levels are the most frequently measured index of sympathetic activity. Physiologic significance is then often extrapolated from measured catecholamine levels. We wished to evaluate the validity of extrapolating from the in vitro to the in vivo adrenergic environment. In this study, guanadrel sulfate (Hylorel; Pennwalt Pharmaceuticals), which inhibits noradrenaline storage in and release from the sympathetic nerve terminal, was added to diuretic monotherapy in patients with essential hypertension. ${ }^{8}$ With this altered adrenergic environment we wanted to answer the following questions: (a) Would plasma catecholamine levels (a frequent index of sympathetic drive) fall during guanadrel therapy? (b) Would platelet $\alpha_{2}$-receptor number change during therapy with a drug that reduces sympathetic drive? (c) Would sensitivity to exogenous catecholamines increase? (d) Would in vitro measures of sympathetic function (plasma catecholamines and 
Table I. Comparison of supine baseline* hemodynamic and biochemical data before and after addition of guanadrel to diuretic monotherapy

\begin{tabular}{lccc}
\hline & Study 1 & Study 2 & P value \\
\hline HR (bpm) & $77 \pm 14$ & $63 \pm 13$ & $<0.001$ \\
SBP (mm Hg) & $135 \pm 14$ & $127 \pm 13$ & $<0.02$ \\
DBP (mm Hg) & $76 \pm 9$ & $67 \pm 5$ & $<0.001$ \\
FABF (ml/100 ml fore- & $4.7 \pm 2.2$ & $4.3 \pm 1.6$ & 0.71 \\
$\quad$ arm volume/min) & & & \\
Plasma NE (pg/ml) & $303 \pm 107$ & $170 \pm 46$ & $<0.01$ \\
Plasma E (pg/ml) & $79 \pm 25$ & $60 \pm 24$ & 0.07 \\
PRA (ng Al/ml/hr) & $5.8 \pm 3.9$ & $4.6 \pm 3.3$ & 0.20 \\
Platelet $\alpha_{2}$-receptors & $204 \pm 77$ & $301 \pm 150$ & $<0.02$ \\
$\quad(\mathrm{fmol} / \mathrm{mg})$ & & & \\
\hline
\end{tabular}

$\mathrm{HR}=$ Heart rate; $\mathrm{SBP}=$ intra-arterial systolic blood pressure; $\mathrm{DBP}=$ intra-arterial diastolic blood pressure; $\mathrm{FABF}=$ forearm blood flow; $\mathrm{NE}=$ norepinephrine; $\mathbf{E}=$ epinephrine; $\mathrm{PRA}=$ plasma renin activity; $\mathrm{AI}=$ angiotensin $\mathrm{I}$.

*After 30 minutes of rest.

platelet $\alpha_{2}$-receptors) correlate with in vivo measurements of $\alpha$-adrenergic physiologic responses in the forearm and pupil?

\section{METHODS}

Subjects. Eleven white patients (10 men and one woman) between 28 and 50 years old $(\bar{X} \pm S D=$ $36 \pm 6$ years) who were receiving diuretic monotherapy with suboptimally controlled casual blood pressure $(>140 \mathrm{~mm} \mathrm{Hg}$ systolic or $>90$ diastolic $\mathrm{mm} \mathrm{Hg}$ in the office or $>130$ systolic or $>85$ diastolic at home) were enrolled. Subjects underwent complete history, physical, and routine laboratory examinations before entry into the study. All were healthy except for mild hypertension. They signed a written, informed consent form approved by the Hospital Committee for Human Research.

Study design. The guanadrel study was an openlabel, nonrandomized evaluation of physiologic and biochemical variables before and again 3 weeks after the start of guanadrel sulfate therapy. After the first study, guanadrel was begun at $5 \mathrm{mg}$ twice a day for the first 5 to 7 days. If blood pressures measured at home had not fallen to $<130 / 85 \mathrm{~mm} \mathrm{Hg}$ or by $10 \mathrm{~mm} \mathrm{Hg}$, the dosage was increased to $10 \mathrm{mg}$ twice a day. Eight subjects achieved the target blood pressure level with guanadrel, $10 \mathrm{mg} /$ day, in addition to their diuretic. Of the three remaining subjects, one received guanadrel, $5 \mathrm{mg}$ twice a day, another took $15 \mathrm{mg}$ twice a day, and a third took $30 \mathrm{mg}$ twice a day. Subjects received the final dose of guanadrel 3 hours before each physiologic study.

Measurements. Blood pressure was measured first by mercury and cuff sphygmomanometry and subsequently in intra-arterial recordings.

Forearm blood flow was measured by venous occlusion, strain gauge plethysmography. The D. E. Hokanson, Inc. EC-3 plethysmograph and E-10 rapid cuff inflator were connected to the polygraph and recorder as described below.

The method for pupillary measurement has been described in detail. ${ }^{9}$ In brief, pupil size was recorded with a binocular pupillograph for 30 seconds under standardized lighting conditions. Thirty measurements of pupil size during the final 3 seconds were averaged both before and 1 hour after phenylephrine dosing. The increase in size of the right pupil (1\% phenylephrine was always instilled into the right eye) minus the change in the size of the control (left) pupil equalled the mydriatic response to $1 \%$ phenylephrine at 1 hour.

Plasma catecholamine ${ }^{10}$ and plasma renin activity ${ }^{11}$ assays were performed as previously described. To determine platelet membrane preparation and $\left[{ }^{3} \mathrm{H}\right]$ yohimbine binding, $50 \mathrm{ml}$ venous blood was immediately mixed with $1 / 9$ volume of ACD $(0.8 \mathrm{gm}$ citric acid, $2.2 \mathrm{gm}$ trisodium citrate, and $2.45 \mathrm{gm}$ dextrose per 100 $\mathrm{ml}$ ). After centrifugation for 7 minutes at $200 \times \mathrm{g}$, the platelet-rich plasma was adjusted to $\mathrm{pH} 6.5$ and centrifuged for 15 minutes at $2000 \times \mathrm{g}$. The platelet pellet was resuspended in buffer $(150 \mathrm{mmol} / \mathrm{L} \mathrm{NaCl}, 1 \mathrm{mmol} /$ $\mathrm{L}$ EDTA, and $20 \mathrm{mmol} / \mathrm{L} \mathrm{TrisCl}$ at $\mathrm{pH} \mathrm{7.6)}$ and centrifuged again. The pellet was suspended in $10 \mathrm{ml}$ homogenization buffer $(10 \mathrm{mmol} / \mathrm{L}$ TrisCl at $\mathrm{pH} 7.6,5$ $\mathrm{mmol} / \mathrm{L}$ EDTA, and $0.25 \mathrm{~mol}$ sucrose) and homogenized with five strokes of a "zero-clearance" homogenizer (Model K886030; Kontes Co.). The membrane fraction was collected by centrifugation for 20 minutes at $43,000 \times \mathrm{g}$. The pellet was resuspended in $10 \mathrm{ml}$ TME buffer $(50 \mathrm{mmol} / \mathrm{L}$ TrisCl at $\mathrm{pH} 7.6,10 \mathrm{mmol} /$ $\mathrm{L} \mathrm{MgCl}_{2}$, and $1 \mathrm{mmol} / \mathrm{L}$ EGTA), then washed three times by pelleting and resuspending in TME buffer. $\left[{ }^{3} \mathrm{H}\right]$ Yohimbine binding ( 1 to $20 \mathrm{nmol} / \mathrm{L}$ ) was measured in triplicate as described. ${ }^{12}$ Nonspecific binding was determined in the presence of $10^{-5} \mathrm{~mol} / \mathrm{L}$ yohimbine. Scatchard plots of specific $\left[{ }^{3} \mathrm{H}\right]$ yohimbine binding were prepared and maximum binding $\left(\mathrm{B}_{\max }\right)$ and affinity $\left(\mathrm{K}_{\mathrm{d}}\right)$ values were determined from linear least-squares fit of the data.

Protocol. Subjects came to the laboratory at $8 \mathrm{AM}$. Height, weight, baseline pupil size, and forearm volume were measured. Plastic catheters were placed in the left brachial artery and an adjacent vein. After 30 minutes of supine rest, venous blood for plasma catecholamine, plasma renin activity, and platelet $\alpha_{2}$ receptor determinations was drawn. Arterial pressures 


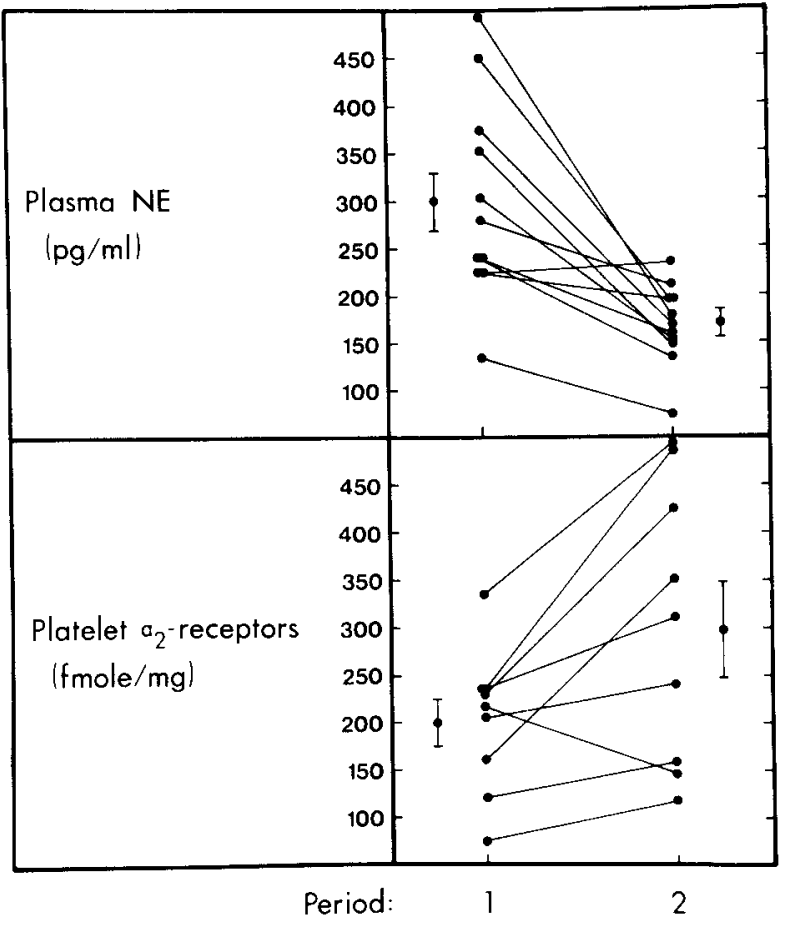

Fig. 1. Mean $( \pm S E)$ and individual paired plasma norepinephrine $(N E)$ and platelet $\alpha_{2}$-receptor values $\left(\left[{ }^{3} \mathrm{H}\right]\right.$ yohimbine $B_{\max }$ ) are shown for subjects in study 1 (diuretics) and study 1 (diuretic and guanadrel). Both the decrease in plasma norepinephrine level and the increase in platelet $\alpha_{2}$-receptors were significant at $P<0.05$.

were monitored and measured by connecting the brachial cannula to a Hewlett-Packard Co. quartz transducer $(1290 \mathrm{~A})$, polygraph $(4568 \mathrm{C})$, and oscilloscope (1308 A) and a Gould Inc. thermal recorder (TA 600).

After baseline supine measurements, a random order infusion of norepinephrine into the brachial artery was started at $0.005,0.01,0.02,0.04$, and $0.08 \mu \mathrm{g}$ per 100 $\mathrm{ml}$ forearm volume per minute. Each norepinephrine infusion lasted 4 minutes and was followed by an 11minute infusion of saline solution. Arterial pressure and forearm blood flow were measured during the last minute of each norepinephrine infusion and at each baseline saline solution infusion period. One hour before the completion of the hemodynamic measurements, $40 \mu \mathrm{l}$ $1 \%$ phenylephrine was instilled into the lower conjunctival sac of the right eye. The study ended with recording of pupil size.

Statistical analysis. Data are reported as the $\overline{\mathrm{X}} \pm$ SD. Comparisons of variables between the two studies were made by the paired $t$ test. Statistical significance was defined by a $P$ value $<0.05$.



Fig. 2. Scatchard plot in one subject of $\left[{ }^{3} \mathrm{H}\right]$ yohimbine binding to platelet membranes during the first study (diuretic alone; -) and the second study (diuretic with guanadrel; $\mathbf{\Delta}$ ). The $\mathbf{B}_{\max }(\mathrm{x}$-intercept) increased during guanadrel therapy from 160 to $353 \mathrm{fmol} / \mathrm{mg}$ protein, while the $\mathrm{K}_{\mathrm{d}}$ (affinity = slope) did not change.

\section{RESULTS}

In our 11 subjects, casual blood pressure at the first visit was $138 \pm 13 / 89 \pm 7 \mathrm{~mm} \mathrm{Hg}$, height was $180 \pm 7 \mathrm{~cm}$, and weight was $210 \pm 37 \mathrm{lb}$. Values for heart rate, intra-arterial blood pressure, forearm blood flow, plasma catecholamine levels, plasma renin activity, and platelet $\alpha_{2}$-receptors after 30 minutes supine rest are listed in Table I. Addition of guanadrel lowered supine heart rate and intra-arterial systolic and diastolic pressures. Forearm blood flow did not change, and plasma norepinephrine levels were reduced. Although plasma renin activity and plasma epinephrine levels tended to fall, the differences were not statistically significant.

Platelet $\alpha_{2}$-receptor number increased as determined by Scatchard plots of $\left[{ }^{3} \mathrm{H}\right]$ yohimbine binding. Because two specimens were lost, complete data on platelet $\alpha_{2}-$ 


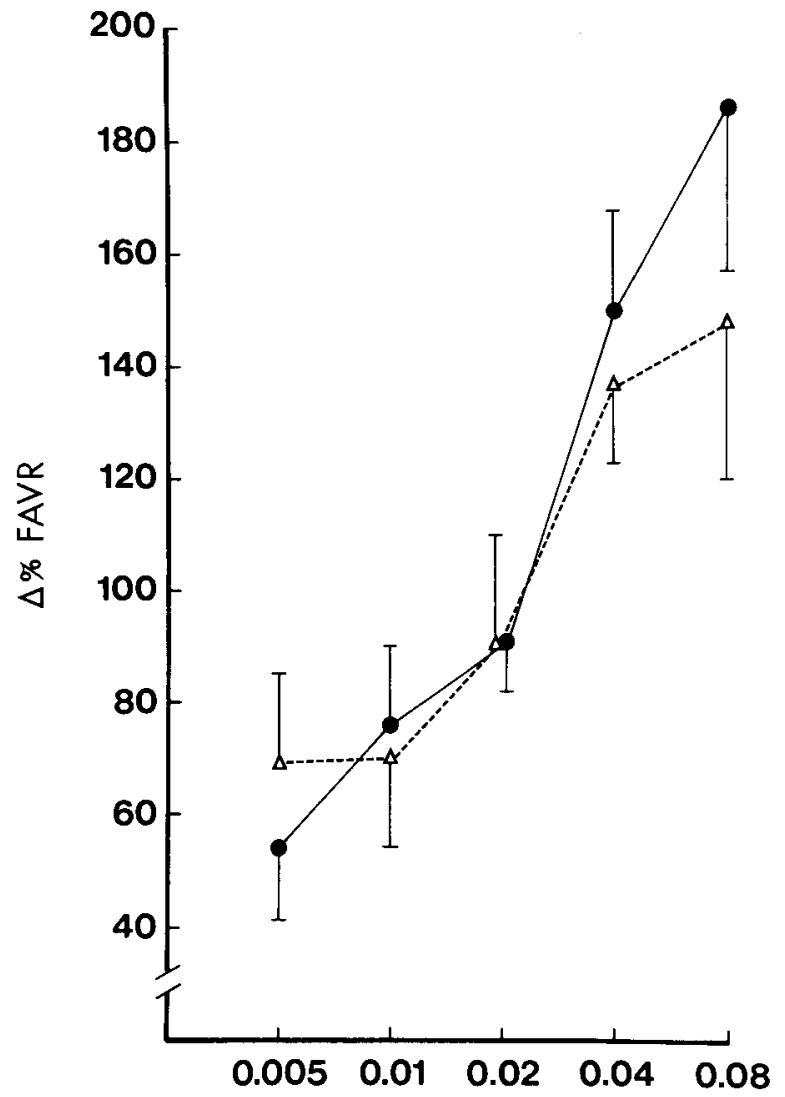

i.a. NE $(\mu \mathrm{g} / 100 \mathrm{ml} / \mathrm{min})$

Fig. 3. Group $\bar{X} \pm \mathrm{SE}$ of the percentage increase in forearm vascular resistance ( $\triangle \% F A V R)$ in response to five doses of intra-arterial norepinephrine (i.a. $N E$ ) given in random sequence in study 1 (diuretics; $\triangle$ ) and study 2 (diuretic with guanadrel; $\bullet$ ). No significant differences were noted at any point on the dose-response curves when the two studies were compared.

receptors were available for only nine subjects. As shown in Fig. 1, eight of the nine subjects showed an increase in $B_{\max }(P<0.02)$, while 10 of 11 had a reduction in norepinephrine levels $(P<0.01)$. The subject with a decreased $B_{\max }$ during the guanadrel trial received the lowest dose of the drug, $5 \mathrm{mg}$ twice a day, and was the only subject without a reduction in the plasma norepinephrine level. However, in the whole group we found no significant correlation between either the absolute $(r=-0.39)$ or percentage $(r=$ $-0.31)$ increase in $\alpha_{2}$-receptors and the reduction in plasma norepinephrine level.

The amount of platelet protein recovered before and during guanadrel therapy was unchanged $(3.2 \pm 1.1$ vs $2.8 \pm 1.4 \mathrm{mg}$ ). This suggests that the increase in

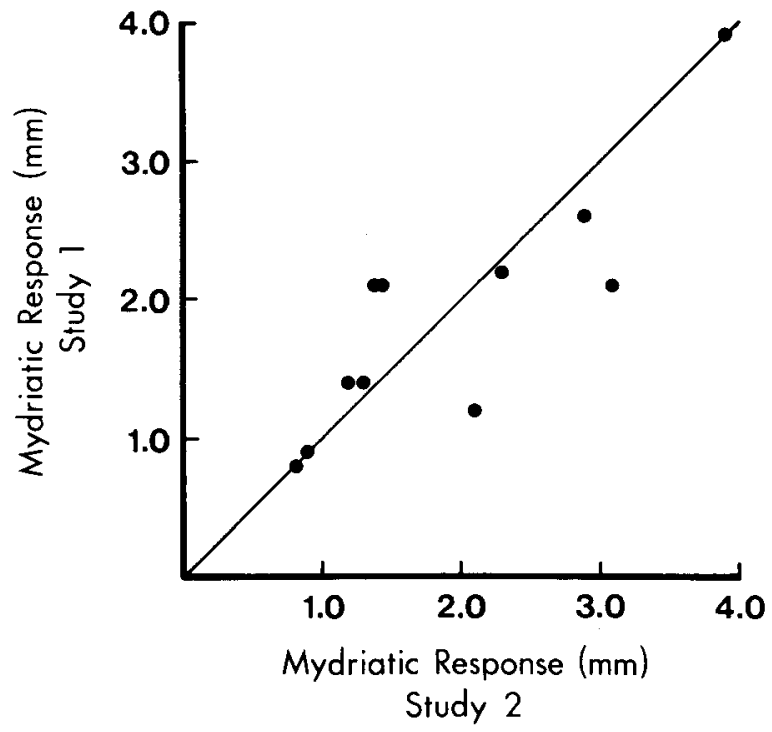

Fig. 4. The mydriatic response for each subject comparing studies 1 and 2 as shown in relationship to the line of identity. As shown, most of the points fell close to the line of identity. This suggests that $\alpha_{1}$-receptor-mediated pupillary mydriasis did not change with addition of guanadrel.

yohimbine binding was due to an increase in the number of binding sites rather than a decrease in the amount of protein recovered. While platelet $\alpha_{2}$-receptor number increased, the $K_{d}$ for yohimbine did not change during guanadrel therapy $(5.4 \pm 0.5$ vs. $5.0 \pm 0.8 \mathrm{nmol})$. Fig. 2 illustrates this increased $B_{\max }(x$-intercept) without change in $K_{d}$ (slope) in one subject. Guanadrel inhibited $\left[{ }^{3} \mathrm{H}\right]$ yohimbine binding at high concentrations, with half-maximal inhibition at $50 \mathrm{mmol} / \mathrm{L}$.

The percent forearm vasoconstrictor responses to locally infused norepinephrine (Fig. 3) and the pupillary mydriatic response to $1 \%$ ophthalmic phenylephrine (Fig. 4) did not change.

\section{DISCUSSION}

Addition of guanadrel to diuretic therapy reduced supine heart rate and intra-arterial blood pressure. Guanadrel also reduced the supine baseline plasma norepinephrine level. These declines are probably explained by the known ability of the drug to reduce noradrenaline storage in and release from the postganglionic sympathetic nerve terminal. ${ }^{8}$ Platelet $\alpha_{2}$-receptor number increased significantly, presumably in response to the reduced sympathetic drive. The effect of guanadrel on platelet $\alpha_{2}$-receptor number is not likely to be due to a direct interaction with the $\alpha_{2}$-receptors, because guanadrel inhibits $\left[{ }^{3} \mathrm{H}\right]$ yohimbine binding only 
at very high concentrations (half-maximal inhibition at $50 \mathrm{mmol} / \mathrm{L}$; data not shown). Pupillary mydriasis and forearm vasoconstriction in response to exogenous $\alpha$ agonists did not change.

There are several salient findings of our study. First, plasma levels of norepinephrine, but not epinephrine, fell in response to a drug known to reduce sympathetic drive. The dissociation between the changes in the two measured catecholamines most likely reflects the postganglionic as opposed to central sympatholytic effects of guanadrel. ${ }^{13}$ There is extensive interest in the utility of venous plasma catecholamine levels for the assessment of sympathetic nervous system activity. ${ }^{14,15}$ It is evident that significant differences in regional release can occur without being reflected in the systemic venous catecholamine measurement. ${ }^{16}$ It is also known that differences in reuptake between individuals may complicate interindividual comparisons. ${ }^{17}$ However, our data further substantiate the value of plasma norepinephrine levels as an index of intraindividual changes in sympathetic drive.

Second, the increase in the number of platelet $\alpha_{2}-$ receptors during guanadrel therapy is of special interest. This is the first study in man to show a consistent increase in platelet $\alpha_{2}$-receptors in response to a welldefined pharmacologic reduction of sympathetic drive and is in agreement with a similar study in rodents. ${ }^{18}$ Patients with disease-related reduction in sympathetic drive such as idiopathic orthostatic hypotension have increased numbers of platelet $\alpha_{2}$-receptors. ${ }^{19,20}$ However, in other studies surgical reduction of sympathetic stimulation by ablation of pheochromocytoma tissue has produced conflicting results of either no change ${ }^{21}$ or an increase ${ }^{19}$ in platelet $\alpha_{2}$-receptors. Administration of the pharmacologic $\alpha_{2}$-agonists guanabenz and clonidine has also produced conflicting findings, showing either no change ${ }^{22}$ or a decrease ${ }^{23}$ in platelet $\alpha_{2}$-receptor number. While it is not clear precisely which factors regulate platelet $\alpha_{2}$-receptor number, it is not likely that circulating levels of plasma catecholamines are an overriding factor. ${ }^{21,24}$

Third, the functional measures of $\alpha$-adrenergic responsiveness, norepinephrine-induced forearm vasoconstriction, and phenylephrine-induced pupillary mydriasis did not change during guanadrel therapy (Figs. 2 and 3). This is in contrast to the consistent decrease in plasma norepinephrine levels and increase in platelet $\alpha_{2}$-receptor number. These observations indicate that caution is needed when extrapolating from differences in or changes of in vitro biochemical measurements of sympathetic activity to in vivo physiologic significance.
The possible explanations for these apparent discrepancies are many. However, we believe the most likely explanations are either that (1) the pupillary and vascular responses are largely $\alpha_{1}$ effects and $\alpha_{1}$-receptors may not upregulate as much as the platelet $\alpha_{2}$ receptors ${ }^{18}$ or (2) the diuretics blunted physiologic responses to catecholamines, ${ }^{25}$ perhaps by altering the intracellular environment. ${ }^{26}$ Additional studies of responses to $\alpha_{2}$-selective agonists in subjects not taking diuretics should answer these questions.

In summary, addition of guanadrel to diuretic monotherapy reduced blood pressure and heart rate in 11 patients with essential hypertension. This reduction was accompanied by a reduction in sympathetic drive (plasma norepinephrine level) and an increase in platelet $\alpha_{2}$-receptors. Despite these changes, physiologic responses to exogenous $\alpha$-agonists did not change. Consequently, extrapolations from in vitro measurements of sympathetic activity to in vivo physiologic significance may be incorrect. There are many potential explanations for this apparent dichotomy and they deserve further investigation.

We are indebted to our technical and data analysis staff of J. Mertens, M. Elkins, D. Rogers, D. Brant, M. Rapai, L. Vadnay, N. Schork, Olga Szamraj, and Mark Zamorski.

\section{References}

1. Julius S, Esler M. Autonomic nervous cardiovascular regulation in borderline hypertension. Am J Cardiol 1975;36:685-96.

2. Esler M, Julius S, Randall O, Ellis C, Kashima T. Relation of renin status to neurogenic vascular resistance in borderline hypertension. Am J Cardiol 1975;36:708-15.

3. Esler M, Julius S, Zweifler A, Randall O, Harburg E, Gardiner H, DeQuattro V. Mild high-renin essential hypertension. N Engl J Med 1977;296:405-11.

4. Meier A, Weidmann P, Grimm M, et al. Pressor factors and cardiovascular pressor responsiveness in borderline hypertension. Hypertension 1981;3:367-72.

5. Phillip TH, Distler A, Cordes U. Sympathetic nervous system and blood pressure control in essential hypertension. Lancet 1978;2:959-63.

6. Doyle A, Fraser J, Marshall R. Reactivity of forearm vessels to vasoconstrictor substance in hypertensive and normotensive subjects. Clin Sci 1959;18:441-53.

7. Amann FW, Bolli P, Kiowski W, et al. Enhanced alphaadrenoreceptor-mediated vasoconstriction in essential hypertension. Hypertension 1981;3(suppl I):I1 19-23.

8. Freyburger WA, Peterson LJ, Kaiser DG, et al. Clinician's brochure on U 28,228 D (Cl-1388R). Kalamazoo, Mich: The Upjohn Company, 1968.

9. Egan B, Neubig R, Schneider R, Julius S. Methods for measuring vascular and nonvascular alpha-receptor sen- 
sitivity in man. Proceedings of the Symposium on Adrenoceptors, Calcium and Exitation-Contraction Coupling: Mechanisms and Pharmacological Interference Satellite. J Cardiovasc Pharm. (in press)

10. Peuler JD, Johnson GA: Simultaneous single isotope radioenzymatic assay of plasma norepinephrine, epinephrine and dopamine. Life Sci 1977;21:625-36.

11. Haber E, Koerner T, Page LB, Kliman B, Purnode A. Application of a radioimmunoassay for angiotensin $I$ to the physiologic measurement of plasma renin activity in normal healthy subjects. J Clin Endocrinol Metab 1969;29:1349-55.

12. Neubig RR, Brasier R, Szamraj O. Large-scale purification of alpha $a_{2}$ adrenergic receptor enriched membranes from human platelets. Biochem Biophys Acta. (Submitted for publication)

13. Leveston SA, Shah SD, Cryer P. Cholinergic stimulation of norepinephrine release in man. J Clin Invest 1979;64:374-80.

14. Goldstein DS, McCarty R, Polinsky RJ, Kopin IJ. Relationship between plasma norepinephrine and sympathetic neural activity. Hypertension 1983;5:552-9.

15. Ibsen H, Julius S. Pharmacologic tools for assessment of adrenergic nerve activity in human hypertension. Fed Proc 1984;43:61-5.

16. Brown M, Jenner D, Allison D, Dollery C. Variations in individual organ release of noradrenaline measured by an improved radioenzymatic technique; limitations of peripheral venous measurements in the assessment of sympathetic nervous activity. Clin Sci 1981;61:585-90.

17. Esler M, Jackman G, Bobik A, et al. Norepinephrine kinetics in essential hypertension. Defective neuronal uptake of norepinephrine in some patients. Hypertension 1981;3:149-56.

18. Bylund D, Martinez J, Pierce D. Regulation of autonomic receptors in rat submandibular gland. Mol Pharmacol 1981;21:27-35.

19. Chobanian A, Tifft C, Sackel H, Pitruzella A. Alpha and beta-adrenergic receptor activity in circulating blood cells of patients with idiopathic orthostatic hypotension and pheochromocytoma. Clin Exp Hypertens [A] 1982; 4,5:793-806.

20. Kafka MS, Polinsky RJ, Williams A. Alpha-adrenergic receptors in orthostatic hypotension syndromes. Neurology (Cleveland) 1984;34:1121-5.

21. Pfeifer M, Ward K, Malpass T, et al. Variations in circulating catecholamines fail to alter human platelet alpha2 adrenergic receptor number or affinity for $\left[{ }^{3} \mathrm{H}\right]$ yohimbine or $\left[{ }^{3} \mathbf{H}\right]$ dihydroergocryptine. J Clin Invest 1984; 74:1063-72.

22. Motulsky HJ, O'Connor DT, Insel PA. Platelet $\alpha_{2}$-adrenergic receptors in treated and untreated essential hypertension. Clin Sci 1983;64:265-72.

23. Brodde $\mathrm{OE}$, Anlauf $\mathrm{M}$, Graben $\mathrm{N}$, Bock $\mathrm{KD}$. In vitro and in vivo downregulation of human platelet $\alpha_{2}$-adrenoceptors by clonidine. Eur J Clin Pharmacol 1982; 23:403-9.

24. Snavely MD, Motulsky HJ, O'Connor DT, Ziegler MG, Insel PA. Adrenergic receptors in human and experimental pheochromocytoma. Clin Exp Hypertens [A] 1982;4,5:829-48.

25. Weidmann PM, Grimm M, Meier A, et al. Pathogenic and therapeutic significance of cardiovascular pressor reactivity as related to plasma catecholamines in borderline and established essential hypertension. Clin Exp Hypertens 1980;2:427-49.

26. Erne P, Bolli P, Burgisser E, et al. Correlation of platelet calcium with blood pressure. Effect of antihypertensive therapy. N Engl J Med 1984;310:1084-8. 